March/April 2003, Volume 9, Issue 2

\title{
Effects of a 3-Tier Pharmacy Benefit Design on the Prescription Purchasing Behavior of Individuals With Chronic Disease
}

KAVITA V. NAIR, PhD; PAMELA WOLFE, MS; ROBERT J. VALUCK, PhD; MARIANNE M. MCCOLLUM, PhD; JULIE M. GANTHER, PhD; and SONYA J. LEWIS, RPh

\section{ABSTRACT}

OBJECTIVE: To evaluate the impact of 3-tier (copayment) pharmacy benefit structures on medication utilization behavior.

METHODS: A pretest-posttest quasi-experimental design was employed. Chronic disease sufferers $(\mathrm{N}=8,132)$ from a health plan were classified into the following groups: (a) 2-tier copayment moving to a 3-tier structure, ("converting" group), (b) 2-tier staying in a 2-tier structure and, (c) 3-tier staying in a 3-tier structure. The latter 2 were "comparison" groups. Two 7-month time periods were determined: the "preperiod" (June through December 2000) and the "postperiod" (January through July 2001) for a change in pharmacy benefit structure. Pharmacy claims data were used for data collection. Statistical analyses included bivariate tests to evaluate predifferences and postdifferences across study groups. Maximum likelihood estimates from a repeated measures model were used to examine changes in formulary compliance and generic use rates. Discontinuation of nonformulary medications was evaluated using logistic regression.

RESULTS: Controlling for demographics, number of comorbidities, disease state, and pharmacy benefit structure, the formulary compliance rate increased by $5.6 \%$ for the converting group. No significant increases were seen for the comparison groups. Generic use rates increased by 6 to 8 absolute percentage points for all groups (3.3\% to $4.9 \%$ adjusted rates). Converting group members were 1.76 times more likely to discontinue their nonformulary medication than those in the 2-tier comparison group and 1.49 times more likely than those in the 3-tier comparison group.

CONCLUSIONS: These findings suggest that shifting individuals from a 2-tier to a 3-tier drug benefit copayment structure resulted in changes in medication utilization. Decision makers need to balance these changes with the potential dissatisfaction that members may express in paying higher copayments.

KEYWORDS: 3-tier, Cost Sharing, Prescription utilization

J Managed Care Pharm. 2003(9)2:123-133

\section{Authors}

KAVITA V. NAIR, PhD, is an Assistant Professor; ROBERT J. VALUCK, PhD, is an Assistant Professor; and MARIANNE M. MCCOLLUM, PhD, is an Assistant Professor, University of Colorado Health Sciences Center, School of Pharmacy, Denver; PAMELA WOLFE, MS, Wolfe Statistical Consulting, LLC, Denver, Colorado; JULIE M. GANTHER, PhD, is an Assistant Professor, University of Iowa, College of Pharmacy, Iowa City; SONYA J. LEWIS, RPh, is Pharmacy Director, Anthem Blue Cross Blue Shield of Colorado, Denver.

AUTHOR CORRESPONDENCE: Kavita V. Nair, PhD, Assistant Professor, University of Colorado Health Sciences Center, School of Pharmacy, 4200 East Ninth Ave, Box C-238, Denver, CO 80262. Tel: (303) 315-0811;

Fax: (303) 315-4630; E-mail: Kavita.Nair@uchsc.edu

Copyright $\odot$ 2003, Academy of Managed Care Pharmacy. All rights reserved.
Editor's note: "Impact of Multi-tiered Pharmacy Benefits on Attitudes of Plan Members With Chronic Disease States," by several of the same authors, was published in the November/December 2002 issue of JMCP. That article examined health plan member attitudes regarding the increased cost sharing and experience in 3-tier drug benefit plans. The current article examines actual prescription utilization behavior when individuals move into a 3-tier plan.

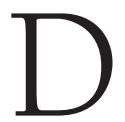
ouble-digit increases in the cost of pharmaceuticals have prompted managed care plans to identify ways to blunt some of these cost increases while simultaneously trying to maintain a choice of products for beneficiaries. ${ }^{1,2}$ These increasing costs have resulted in beneficiaries participating more in their health care decisions, particularly in their choices for prescription medications. This increased awareness among beneficiaries has supported the relatively new concept in pharmacy benefits known as multi-tiered (copayment) plans. ${ }^{2}$ Multi-tiered pharmacy benefits are based on the assumption that drugs within a medication class are relatively interchangeable. ${ }^{3}$ Patients have to pay an out-of-pocket difference or a higher copayment for more expensive or nonformulary medications.

An early form of the multi-tiered pharmacy benefit structure was the 2-tier copayment plan. In 2-tier copayment plans, the lower copay tier is used for formulary-based generic medications, and the second copay tier is for formulary-based, brandname medications. Nonformulary medications typically can be obtained at the brand copayment amount through the health plan's prior-approval process, if the drug benefit plan required such authorization. Two-tier plans are being rapidly replaced by the 3-tier pharmacy benefit plan. In this structure, as with the 2-tier plans, the lowest copayment tier is for formulary-based generic medications. Formulary brand-name medications constitute the second, or middle, copayment tier, and the highest copayment, or the "third tier," is usually reserved for nonformulary medications. Medications in the third tier may also include lifestyle or cosmetic drugs (e.g., smoking cessation, weight-loss aids, or antifungal drugs) or higher priced brandname drugs. In some drug plans, a prior approval may also apply to some brand drugs in either copayment tier in a 3-tier drug design.

In 2002, 3-tier pharmacy benefit plans became a dominant pharmacy benefit structure among prescription drug plans. ${ }^{4}$ Managed care decision makers argue that the 3-tier pharmacy benefit structure can help contain the growing cost of pharma- 
ceuticals by shifting some of the cost of more expensive medications to the beneficiaries who use these products. Three-tier copayment structures can also improve adherence to the health plan's formulary by using financial (copayment) incentives to encourage beneficiaries to purchase medications assigned to the lower copay tiers. ${ }^{5}$

The question that begs for evaluation is how beneficiaries respond to the 3-tier pharmacy benefit structures. Proponents of the 3-tier benefit structure suggest that beneficiaries may realize some benefits when managed care plans implement a 3-tier pharmacy benefit structure. For example, a 3-tier pharmacy benefit structure gives beneficiaries a broader choice of medications by extending coverage to products in the third tier that may not have been previously covered. ${ }^{1}$ In support of this notion, Holdford et al. found that product choice was the most important attribute cited by beneficiaries in selecting a prescription drug plan. ${ }^{6}$ Three-tier plans could potentially provide more choice to beneficiaries, but at a higher out-ofpocket cost.

Three-tier copayment plans may also reduce the need for other cost-containment mechanisms such as prior authorizations or step therapy that could function as barriers to medication access. ${ }^{4}$ In a 2 -tier pharmacy benefit structure, beneficiaries are given a choice of medications, but the choice may be limited to brand or generic medications. In some 2-tier copayment drug plans, beneficiaries had to get approval from the health plan through mechanisms such as prior authorizations or had to pay out-of-pocket costs for the nonformulary product. Sometimes this prior approval would require beneficiaries to demonstrate that they had failed the lower-cost formulary alternatives before the health plan would approve the nonformulary medication. A 3-tier plan can eliminate the need for the beneficiary to go through this administrative hurdle by simply paying a higher copayment for the nonformulary medication.

Critics of the 3-tier pharmacy benefit structure may contend that higher copayments for "essential" medications, in particular, may restrict access to certain prescription drugs for persons in vulnerable populations. Essential medications might be defined as those whose withdrawal could have serious effects on health status. ${ }^{7}$ Individuals on such medications may include those with chronic disease states who often work with their physicians to arrive at the optimal drug or combination therapy after a period of trial and failure. The resulting drug therapies may be less easily interchanged with lower-cost therapeutic alternatives. Vulnerable populations in 3-tier pharmacy benefit structures may have to weigh the increase in copayment between the various tiers with the differences in the perceived benefits of purchasing medications in each tier. ${ }^{8}$ This multi-tier method of pricing prescription drug benefits likely increases the need for information to assist beneficiaries in making appropriate choices among their prescription options. While beneficiaries may be able to make informed decisions about their drug therapy choices for certain disease states (e.g., impo- tence), their decision making may be more difficult for chronic disease states such as hypertension, where the decisions may be more complex and involve more directly the clinical assessments and judgment of the prescriber or pharmacist. ${ }^{8}$

Health plans are adopting 3-tier pharmacy benefit plans as a major cost-containment mechanism and shifting members from their current 2-tier to a 3-tier pharmacy benefit structure to increase formulary compliance and the utilization of lowercost medications. ${ }^{9}$ For beneficiaries in a 2-tier pharmacy benefit plan already accustomed to a differential copayment structure, a transition to a 3-tier pharmacy benefit plan is probably fairly comprehensible. Nevertheless, higher copayments for certain drugs may cause beneficiaries to make choices: whether to stay on their current medication by paying more, switch to a formulary or other alternative that has a lower copayment amount, or discontinue the medication. For chronic disease sufferers who have been stabilized on a medication and are accustomed to its effects, these choices may be harder to make and may be followed by a variety of different responses depending on personal financial condition, health status, and perceived health benefits. ${ }^{3,10}$

Past research has shown that moving individuals from a 2-tier copayment plan ( $\$ 7$ generic copayment and $\$ 12$ brand copayment) to a 3 -tier plan $(\$ 8 / \$ 15 / \$ 25)$ plan resulted in lower prescription utilization and expenditures and reduced net plan costs, with no significant differences found in physician office visits, inpatient, or emergency room use rates. ${ }^{11}$ In the current managed care environment, health plans typically offer a variety of pharmacy benefit structures to their members. There is no standardization among health plans in 3-tier copayment designs; it may involve simply adding a third copayment tier to an existing 2-tier copayment design or lowering or otherwise altering copayments in the first and second tiers and adding a higher copayment tier to the new drug benefit structure.

The primary goal of this study was to examine the effects of a 3-tier pharmacy benefit copayment structure on prescription drug utilization behavior for health plan members with chronic disease states. Of specific interest were the effects of drug benefit design changes on drug utilization measures such as formulary compliance, generic use rates, and discontinuation rates for nonformulary medications for patients with one or more of 5 selected chronic disease states.

\section{Methods}

The research design was pretest-posttest quasi-experimental with comparison group to examine enrollees in 2- and 3-tier pharmacy benefit plans of a large managed care plan in the western United States that included health maintenance organization (HMO), preferred provider organization (PPO), and Medicare+Choice members. The goal of sample selection was to obtain a representative group of plan members in 2- and 3-tier pharmacy benefit plans that might be most vulnerable to the changes in cost sharing as a result of their health status. 
Five chronic disease states were chosen for prescription medications: hypertension, diabetes, dyslipidemia, gastroesophageal reflux disease (GERD), and arthritis. These 5 categories of medication were selected to minimize the potentially confounding effects of seasonal variation in prescription drug use.

\section{Inclusion Criteria}

Pharmacy claims data were used for sample selection. Standard data collected included prescription fill date, days supply, formulary/nonformulary indicator, generic/brand indicator, new prescription or refill indicator, ingredient cost, dispensing and administrative fees, and copayment amount; net plan cost was calculated from these data fields. The type of drug dispensed and its drug class were determined using the generic product identifier (GPI) code (Medispan GPI classification system). Drug classes using the GPI code were used to assign members to one or more of the 5 disease states; i.e., a given member could be assigned to more than one disease category if multiple classes of drugs were utilized.

All 3 drug benefit groups included members from a random sample of 25,008 health plan members who had at least 2 prescriptions filled for any one of the 5 disease states during the 5 months (from January 1 to May 31, 2000) prior to the start of the study period. The observation period for the study was a total of 14 months, 7 months in the preperiod (before a change in pharmacy benefit design) and 7 months in the postperiod (after a change in pharmacy benefit design). The preperiod began on June 1, 2000, and ended on December 31, 2000. On January 1, 2001, pharmacy benefit structures changed, signaling the beginning of the postperiod, which began on January 1 , 2001, and ended on July 31, 2001. Additionally, no other changes in health plan design (such as increases in office visit copayments) occurred during the study period.

From this sample of $25,008,8,132$ members were selected based on continuous enrollment during both the preperiods and postperiods and experienced a change from either a 2-tier to a 3-tier benefit structure or no change, remaining in a 2-tier or a 3-tier copay design. These 8,132 health plan members were classified into the following 3 study groups: (a) 2-tier copayment moving to a 3-tier pharmacy benefit structure, referred to as the "converting" group; (b) 2-tier staying in a 2-tier pharmacy benefit structure; and (c) 3-tier staying in a 3-tier pharmacy benefit structure. The latter 2 were the "comparison" groups. For those who remained in a 2- or 3-tier plan during the postperiod, movement within plans (2-tier to another 2-tier or 3-tier to another 3 -tier structure) also occurred, and, thus, all 3 study groups experienced some change in their prescription benefit plan.

\section{Study Variables}

Study measures obtained from pharmacy claims and membership data included the following: (a) age, (b) gender, (c) disease state (based on the classification of individuals by GPI codes using pharmacy claims data), (d) time period (preintervention versus postintervention period), and (e) outpatient chronic disease indicator based on prescription claims for one year from January 1 to December 31, 2000. The chronic disease indicator (CDI) approximates the number of chronic diseases of each member based on the application to pharmacy claims data of sets of predefined medication classes, which are determined by an expert panel to be indicative of particular chronic disease states. ${ }^{12}$ Higher CDI scores indicate a greater number of chronic illnesses.

\section{Prescription Medication Utilization and Cost Measures}

Medication utilization measures were calculated from pharmacy claims data. Utilization measures included the average number of prescriptions per patient per month and generic use rate, formulary compliance rate; and the medication possession ratio (MPR); a measure of medication compliance. Generic use rate was defined as the number of generic claims (tier 1 ) divided by the total number of claims (copayment tiers 1, 2, and 3). Formulary compliance rate was defined as the formulary prescription claims (copayment tiers 1 and 2) divided by the total number of claims (copayment tiers 1,2, and 3). MPR was defined as the total days supply for a medication divided by the total number of days between the first and last prescription for an individual during the study period..$^{13}$

Prescription cost measures were based on the cost per prescription per patient per month (PPPM) where the cost per prescription was the sum of the ingredient cost, dispensing fee, and administrative fee for each prescription. The 3 prescription cost measures used in the analysis were the median prescription cost per month, median health plan (net) cost per month (determined as ingredient cost + dispensing fee + administrative fee - member copayment), and the median copayment amount PPPM. ${ }^{14}$

Discontinuation rates for nonformulary medications were examined for individuals in all study groups who had a minimum of 2 claims for one of the medications that were on the formulary during the preperiod and were removed during the postperiod. During the postperiod, more than $70 \%$ of the members in the 2-tier comparison groups experienced increases in their copayment amounts either within a different 2-tier structure or in having to assume the full cost of the medication if it was not approved by the health plan. For individuals in the 3-tier comparison group and those in the converting group, the nonformulary medications were removed from the second tier and shifted to the third tier, resulting in increased copayment amounts that these individuals faced for their medications.

Medication classes for nonformulary medications that were examined included calcium channel-blockers, angiotensin II receptor antagonists, angiotensin converting enzyme (ACE) inhibitors, beta-blockers, combination therapies, disease-modifying antirheumatic drugs, nonsteroidal anti-inflammatory medications, bile acid sequestrants, statins, fibric acid derivatives, and proton pump inhibitors. Prescription claims up to a 34-day equivalent were used to determine discontinuation rates. Treatment termination date was defined as the last observed fill 
date for the nonformulary product plus the number of days for which the medication was dispensed in the postperiod. Individuals were classified as "continuing" the nonformulary product in the postperiod if the ratio of their medication possession ratio in the postperiod compared to that in the preperiod for the product was equal to or greater than 0.5. Computing the MPRs in the preperiods and postperiods for the nonformulary product allowed a more accurate evaluation of medication purchasing behavior (as a function of prescription refill data) for each individual by assessing their prescription purchasing behavior after their pharmacy benefits changed relative to their behavior before the change. Thus, if individuals continued to take the nonformulary product in the postperiod with approximately the same regularity as in the preperiod and had a prescription claim for the product that was within 60 days of the end of the postperiod, they were classified as "continuing" the medication.

Individuals who had no claims for the nonformulary product in postperiod or for whom the ratio of post-MPR to pre-MPR was less than 0.5 (i.e., they decreased their use of the medication by more than $50 \%$ in the postperiod) or who did not have a termination date for the product that was within 60 days of the end of the postperiod were classified as "discontinuing" the medication.

The difference in the copayment amount for each of the medications examined in this analysis during the preperiod and postperiod was also determined. For example, if an individual in a 2-tier pharmacy benefit plan of $\$ 10 / \$ 20$ in 2000 was taking a formulary brand-name medication, the copayment cost of that medication would be $\$ 20$. If the individual was now in a 3 -tier pharmacy benefit plan of $\$ 10 / \$ 20 / \$ 35$ in 2001 , and the medication was shifted to the third copayment tier, it would now cost $\$ 35$ and the copayment difference would be $\$ 15$. Discontinuation behavior of nonformulary medications at increasing increments of copayment differences was also examined $(<\$ 10, \$ 15, \$ 20, \$ 25, \$ 30)$.

\section{Statistical Analysis}

Bivariate tests of differences across all study groups were based on a chi-square test for independent proportions for categorical variables, and a $k$-sample median test for continuous variables. Maximum likelihood estimates from a repeated-measures model were used to test for change (preperiod versus postperiod values) in the outcome measures, formulary compliance, and generic use rates. This approach is conceptually the same as multivariate analysis of variance (MANOVA) but avoids the case-wise deletion of subjects with missing assessments (no claim in the preperiod or postperiod data). ${ }^{15}$ Discontinuation of nonformulary medications was evaluated using logistic regression. ${ }^{16}$ Linearity assumptions were tested and variables recoded where the assumption failed. All statistical analyses were performed in SAS, version 8.1. ${ }^{17}$

\section{Results}

\section{Characteristics of the Study Sample}

Members in the 2-tier comparison group were older, more like- ly to be Medicare enrollees, single, and, on average, had more chronic disease states than the other study groups (Table 1 ). The members in the 2-tier comparison group consumed more prescriptions per month and had higher prescription costs, in accordance with their age demographic. The 3-tier comparison group was similar to the converting group in most respects, but the members were primarily in HMO plans and had, on average, the highest monthly copayment amounts compared to the other groups. The subjects in the converting group were primarily in PPO plans, a greater percentage had family, and they had the lowest number of chronic disease states and lower copayment amounts compared to the other 2 groups. Anti-hypertensive medication was the most common drug category among all 3 of the study groups.

There were various copayment structures among the 2 - and 3-tier copayment plans in the sample. In the preperiod, the 2 predominant benefit structures were a $\$ 7 / \$ 152$-tier plan and a $\$ 15 / \$ 25 / \$ 40$ 3-tier plan. More than one third of the sample (34\%) was in a $\$ 7 / \$ 152$-tier benefit structure, with a $\$ 7$ copayment for generic medications (tier 1 ) and a $\$ 15$ copayment for brand-name medications (tier 2), while $22 \%$ were in a $\$ 5 / \$ 15$ plan and $14 \%$ were in a $\$ 5 / \$ 10$-tier copayment plan. A little more than one quarter of the sample $(28 \%)$ was in a $\$ 15 / \$ 25 / \$ 40$ 3-tier pharmacy benefit structure where tier-1 formulary generic medications cost the member $\$ 15$, tier- 2 formulary brand-name medications cost $\$ 25$, and tier-3 nonformulary medications cost $\$ 40$. Less than $2 \%$ of the sample was in other 2- or 3-tier copayment plans such as $\$ 10 / \$ 20$ or $\$ 10 / \$ 20 / \$ 35$ or $\$ 5 / \$ 15 / \$ 30$. In the postperiod, only $17 \%$ were in the $\$ 7 / \$ 15$ 2-tier benefit structure, $45 \%$ were now in the $\$ 15 / \$ 25 / \$ 40,22 \%$ in a $\$ 10 / \$ 20 / \$ 35$, and $6 \%$ in a $\$ 5 / \$ 15 / \$ 30$ 3 -tier pharmacy benefit structure. About 10\% of the sample was in other 2- or 3-tier copayment plans such as $\$ 5 / \$ 10, \$ 9 / \$ 18$, $\$ 10 / \$ 20$, or $\$ 20 / \$ 35 / \$ 50$.

\section{Prescription Utilization and Medication Costs for Tiers 1 to 3 in the Preperiod and Postperiod}

Overall, it appears that in the postperiod there was a shift from formulary brand-name medications toward generic medications for all 3 study groups and an additional shift away from the use of nonformulary medications for the converting group (Table 2). There appears to be a $6 \%$ to $8 \%$ absolute increase in the purchase of generic medications for all 3 of the study groups and a $3 \%$ to $5 \%$ absolute decrease in the use of formulary-based, brand-name medications. As expected, the converting group experienced a decrease $(5 \%)$ in nonformulary prescription purchases, but it was the only study group to do so.

Overall median monthly prescription utilization, health plan costs, and copayment amounts were examined, and the comparisons were conducted on the median differences rather than mean differences since the data were not normally distributed. All 3 groups had increases in the number of prescription claims for medications in copayment tiers 1 and 2 in the postperiod (Table 3 ). The 
TABLE 1 Description of the Continuously Enrolled Population: Demographics, Prescription Utilization, and Cost Measures Before a Change in Pharmacy Benefit Structure

\begin{tabular}{|c|c|c|c|c|}
\hline $\begin{array}{l}\text { Demographic Characteristics*: } \\
(\mathrm{N}=8,132) \\
\text { (June } 1,2000 \text { - December } 31,2000)\end{array}$ & $\begin{array}{l}\text { 2-tier Plan Members } \\
\text { Staying in 2-tier } \\
(\mathrm{n}=715)\end{array}$ & $\begin{array}{l}\text { 3-tier Plan Members } \\
\text { Staying in 3-tier } \\
(\mathbf{n}=1,707)\end{array}$ & $\begin{array}{l}\text { 2-tier Moving } \\
\text { to 3-tier } \\
(\mathrm{n}=5,710)\end{array}$ & $P$-value $\dagger$ \\
\hline $\begin{array}{l}\text { Age } \\
\text { Mean (SD) }\end{array}$ & $61.9(16.3)$ & $48.0(11.0)$ & $49.4(11.2)$ & $<0.0001$ \\
\hline $\begin{array}{l}\text { Gender } \\
\text { Female N (\%) } \\
\text { Male N (\%) }\end{array}$ & $\begin{array}{l}351(49.1 \%) \\
364(50.9 \%)\end{array}$ & $\begin{array}{l}833(48.8 \%) \\
874(51.2 \%)\end{array}$ & $\begin{array}{l}2670(46.8 \%) \\
3040(53.2 \%)\end{array}$ & 0.21 \\
\hline $\begin{array}{l}\text { Type of managed care plan } \\
\text { 1. HMO N (\%) } \\
\text { 2. PPO N (\%) } \\
\text { 3. Medicare + Choice N (\%) }\end{array}$ & $\begin{array}{l}251(35.1 \%) \\
55(7.7 \%) \\
409(57.2 \%)\end{array}$ & $\begin{array}{l}1242(72.8 \%) \\
464(27.2 \%) \\
0\end{array}$ & $\begin{array}{l}1704(29.8 \%) \\
4006(70.2 \%) \\
0\end{array}$ & $<0.0001$ \\
\hline $\begin{array}{l}\text { Family status } \\
\text { 1. Family N (\%) } \\
\text { 2. Single N (\%) }\end{array}$ & $\begin{array}{l}255(35.9 \%) \\
455(64.1 \%)\end{array}$ & $\begin{array}{l}1043(61.6 \%) \\
649(38.4 \%)\end{array}$ & $\begin{array}{l}3615(65.3 \%) \\
1918(34.7 \%)\end{array}$ & $<0.0001$ \\
\hline
\end{tabular}

Number of comorbidities

Chronic Disease Indicator Score

Mean (SD)

$4.2(2.7)$

$3.2(2.2)$

$3.1(2.2)$

$<0.0001$

Number of individuals in each disease state

Hypertension N (\%)

$504(70.5 \%)$

$239(33.4 \%)$

$212(29.7 \%)$

Arthritis N (\%)

Diabetes N (\%)

Gastroesophageal reflux disease N (\%)

$977(57.2 \%)$
$517(30.3 \%)$
$495(29.0 \%)$
$418(24.5 \%)$
$452(26.5 \%)$

$214(29.9 \%)$
$3,157(55.3 \%)$

$1,485(26.0 \%)$

$1,857(32.5 \%)$

$627(11.0 \%)$

\section{$<0.0001$}

$<0.0001$

0.01

$<0.0001$

$1,427(25.0 \%)$

0.01

Prescription utilization:

Average number of prescriptions per

patient per month (PPPM)

Mean (SD)

$1.8(1.4)$

$1.4(1.2)$

$1.2(1.1)$

$<0.0001$

Formulary compliance rate

Mean (SD)

$0.865(0.268)$

$0.856(0.281)$

$0.780(0.346)$

$<0.0001$

Generic utilization $(\mathrm{Rx})$ ratio

Mean (SD)

$0.386(0.360)$

$0.360(0.393)$

$0.368(0.408)$

$<0.0001$

Prescription expenditures:

Average monthly cost per patient

Mean (SD) [Median]

$\$ 83.6$

(\$83.6)

[\$64.6]

(\$105.1)

[\$49.4]

$(\$ 90.4)$

[\$45.7]

Average monthly cost per patient to

the health plan

Mean (SD) [Median]

$\$ 63.6(\$ 74.9)$
$[\$ 48.0]$
$\$ 20.0(\$ 16.5)$
$[\$ 15.6]$

\section{$\$ 51.8(\$ 88.4)$}

$[\$ 27.6]$

Average monthly copayment amount per patient

Mean (SD) [Median]

* Determined from pharmacy claims in 2000

$\dagger P$-value is based on a chi-square test for independent proportions for categorical variables, a 3-sample median test for continuous variables.

magnitude of overall increase in the median number of prescriptions is consistent with that observed by Motheral et al. (2001) and is consistent with a general increase in the volume of prescriptions in 2001, particularly in the drug classes examined in this study. ${ }^{11,18,19}$ For both the 2-and 3-tier comparison groups, tier 1 increased the most in the postperiod. For the converting group, tier 1- and tier 2drugs had similar increases in the postperiod. The greatest change in prescription costs to the health plan was observed for tier-2 medications in all study groups, with the largest absolute increase of $9.4 \%$ in the 3-tier comparison group. In the converting group, individuals on tier-2 medications experienced the highest increase in median copayment amount (a 10.4\% absolute increase) during the postperiod. Smaller increases in the median copayment amounts were observed for tier-3 prescriptions in all 3 of the study groups. 


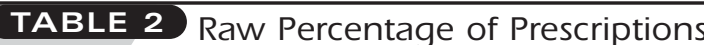 for Copayment Tiers 1 to 3 in Preperiods and Postperiods}

\begin{tabular}{|c|c|c|c|}
\hline Percentage of Prescriptions & Preperiod* & Postperiod $\dagger$ & Difference \\
\hline \multicolumn{4}{|l|}{ 2-tier staying in 2-tier $\$$} \\
\hline Tier 1 丰 & $36 \%$ & $42 \%$ & $6 \%$ \\
\hline Tier 2末 & $53 \%$ & $47 \%$ & $6 \%$ \\
\hline Tier 3 & $11 \%$ & $11 \%$ & $0 \%$ \\
\hline \multicolumn{4}{|l|}{ 3-tier staying in 3-tier $\$$} \\
\hline Tier 1末 & $30 \%$ & $36 \%$ & $6 \%$ \\
\hline Tier 2末 & $57 \%$ & $51 \%$ & $6 \%$ \\
\hline Tier 3 & $13 \%$ & $13 \%$ & $0 \%$ \\
\hline \multicolumn{4}{|l|}{ 2-tier converting to 3 -tier韦: } \\
\hline Tier 1 丰 & $29 \%$ & $37 \%$ & $8 \%$ \\
\hline Tier 2末 & $51 \%$ & $48 \%$ & $3 \%$ \\
\hline Tier 3 & $20 \%$ & $15 \%$ & $5 \%$ \\
\hline \multicolumn{4}{|c|}{$\begin{array}{l}\text { * Percentage of total prescriptions purchased in the preperiod. } \\
\dagger \text { Percentage of total prescriptions purchased in the postperiod. } \\
\ddagger P<0.000 \text {. }\end{array}$} \\
\hline
\end{tabular}

\section{Prescription Utilization for Selected Drug Classes in the Preperiod and Postperiod}

The percentage of prescriptions in copayment tiers 1 to 3 for selected drug classes in all 3 of the study groups during both the preperiods and postperiods were also assessed (results not shown). Tier-3 nonformulary use was inconsistent. The $\mathrm{H}_{2}$ receptor antagonists showed the "expected" behavior in the postperiod for all study groups: an absolute increase in the use of generics ( $4 \%$ to $10 \%$ ), a small absolute decrease in the use of formulary brand-name products ( $1 \%$ to $2 \%$ ), and a larger absolute decrease in the use of nonformulary products (4\% to $5 \%$, ) with the largest decrease (9\%) in the converting group. A substantial reduction in the use of nonformulary products during the postperiod was observed for the converting group, $11 \%$ for calcium channel-blockers and $6 \%$ for alpha glucosidase inhibitors (e.g., miglitol, acarbose). On the other hand, the HMG-CoA reductase inhibitor drug class showed little change in prescription claims for all 3 groups during the postperiod. For drug classes such as NSAIDS, fibric acid derivatives, proton pump inhibitors, and beta-blockers, there was little change in the use of nonformulary medications during the postperiod for the converting group. For salicylates, bile acid sequestrants, sulfonylureas, ACE inhibitors, and diuretics, nonformulary use increased for all study groups in the postperiod.

\section{Formulary Compliance Rates During the Preperiod and Postperiod}

Maximum likelihood estimates from a repeated-measures model were used to examine changes in formulary compliance during the postperiod, controlling for demographics (age, gen- der) number of comorbidities (CDI scores), disease states (one of the 5 diseases being examined), pharmacy benefit structure (2-tier or 3-tier structure), time period (preperiod versus postperiod), and the interaction of the latter 2 terms. All variables that were not significant were eliminated from the saturated model in step-wise fashion to arrive at the final model, which included only those measures that were significantly correlated with the dependent variable. This process eliminated the individual effects of pharmacy benefit structure and time period (the interaction term between the 2 variables was included in the model). The age variable was divided into 3 categories: 18 to 25,26 to 64 , and older than 65 years. The adjusted estimates of formulary compliance for each time period by pharmacy plan type are shown in Table 4. The interaction of time period by pharmacy benefit structure is a significant predictor of formulary compliance. The formulary compliance rates in the comparison groups were similar: $87 \%$ for those in the 2-tier and $88 \%$ for those in the 3-tier comparison group. However, the converting group had a lower formulary compliance rate during the preperiod (81.31\% versus $86.7 \%$ ), which showed an absolute increase of $5.6 \%$ during the postperiod.

The estimates in Table 4 for the different age categories ( 18 to 25 years and older than 65 years) are the difference in mean compliance rates for those age groups, on average, for the entire study period relative to subjects aged 25 to 64 years. The formulary compliance rate for individuals aged 18 to 25 years was higher (an absolute increase of $7.5 \%$ ) than for those members aged between 25 and 64 years. Individuals older than 65 years were more formulary compliant than those aged between 25 and 64 years (absolute difference of 4\%). The CDI variable is centered, and its coefficient estimates the shift in the mean formulary compliance rate for a one-unit change in CDI (the range is 1 to 10). Although significant, the effect is very small and of no apparent practical significance. Finally, the estimates for the 5 disease states also represent a shift in the mean formulary compliance rate. Thus, diabetics are more formulary compliant than those who were not taking prescription medications for diabetes (absolute difference 6.9\%) while individuals with GERD are less formulary compliant than all others (absolute difference 6.3\%).

\section{Generic Use Rates During the Preperiod and Postperiod}

Similar to the formulary compliance analysis, maximum likelihood estimates from a repeated-measures model were used to examine changes in generic use rates in the continuously enrolled population controlling for factors outlined in the previous analysis (results not shown). The interaction of the time period (preperiod versus postperiod) and pharmacy benefit structure (2-tier, 3-tier, 2-3 tier) is also a significant predictor of generic use rates. For all 3 of the study groups, the generic use rates increased in the postperiod. The increase in the generic utilization ratio was highest for the converting group (4.9 absolute percent), followed by the 2-tier comparison group 


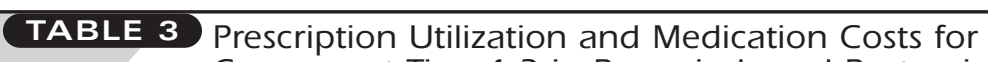
Copayment Tiers 1-3 in Preperiods and Postperiods*

\begin{tabular}{|c|c|c|c|c|c|c|c|c|c|c|c|}
\hline \multirow[b]{2}{*}{$\begin{array}{l}\text { Median number of prescriptions } \\
\text { (Rxs) per patient per month }\end{array}$} & \multicolumn{3}{|c|}{$\begin{array}{l}\text { 2-Tier Plan Members } \\
\qquad(\mathrm{n}=715)\end{array}$} & \multicolumn{3}{|c|}{$\begin{array}{l}\text { 3-Tier Plan Members } \\
\qquad(\mathrm{n}=1,707)\end{array}$} & \multicolumn{3}{|c|}{$\begin{array}{c}\text { Converting Group } \\
(2 \text {-to } 3 \text {-Tier, } \mathrm{n}=5,710)\end{array}$} & \multicolumn{2}{|c|}{ Overall } \\
\hline & $\begin{array}{l}\text { Pre- } \\
\text { period }\end{array}$ & $\begin{array}{l}\text { Post- } \\
\text { period }\end{array}$ & Change & $\begin{array}{l}\text { Pre- } \\
\text { period }\end{array}$ & $\begin{array}{l}\text { Post- } \\
\text { period }\end{array}$ & Change & $\begin{array}{l}\text { Pre- } \\
\text { period }\end{array}$ & $\begin{array}{l}\text { Post- } \\
\text { period }\end{array}$ & Change & $\begin{array}{l}\text { Pre- } \\
\text { period }\end{array}$ & $\begin{array}{l}\text { Post- } \\
\text { period }\end{array}$ \\
\hline Tier 1 & 0.29 & 0.71 & 0.42 & 0.14 & 0.43 & 0.29 & 0.14 & 0.29 & 0.15 & & \\
\hline Tier 2 & 0.71 & 0.86 & 0.15 & 0.57 & 0.71 & 0.14 & 0.29 & 0.57 & 0.28 & & \\
\hline Tier $3 \dagger$ & 0.00 & 0.14 & 0.14 & 0.00 & 0.00 & 0.00 & 0.00 & 0.00 & 0.00 & & \\
\hline Total Rxs PPPM $\dagger$ & 1.00 & 1.71 & 0.71 & 0.71 & 1.14 & 0.43 & 0.43 & 0.86 & 0.43 & 1.00 & 1.28 \\
\hline \multicolumn{12}{|l|}{$\begin{array}{l}\text { Median cost per member to the } \\
\text { health plan }\end{array}$} \\
\hline$\overline{\text { Tier } 1}$ & $\$ 0.45$ & $\$ 2.66$ & $\$ 2.21$ & $\$ 0.04$ & $\$ 0.31$ & $\$ 0.27$ & $\$ 0.04$ & $\$ 0.26$ & $\$ 0.22$ & & \\
\hline Tier 2 & $\$ 31.05$ & $\$ 38.14$ & $\$ 7.09 \S$ & $\$ 15.11$ & $\$ 24.48$ & $\$ 9.37$ & $\$ 11.26$ & $\$ 16.23$ & $\$ 4.97$ & & \\
\hline Tier 3† & $\$ 0.00$ & $\$ 0.14$ & $\$ 0.14$ & $\$ 0.00$ & $\$ 0.00$ & $\$ 0.00$ & $\$ 0.00$ & $\$ 0.00$ & $\$ 0.00$ & & \\
\hline Total health plan cost PPPM $\ddagger$ & $\$ 31.50$ & $\$ 40.94$ & $\$ 9.44$ & $\$ 15.15$ & $\$ 24.79$ & $\$ 9.64$ & $\$ 11.30$ & $\$ 16.49$ & $\$ 5.19$ & $\$ 33.45$ & $\$ 31.94$ \\
\hline \multicolumn{12}{|l|}{$\begin{array}{l}\text { Median monthly copayment amount } \\
\text { per member }\end{array}$} \\
\hline Tier 1 & $\$ 2.14$ & $\$ 5.52$ & $\$ 3.38 \S$ & $\$ 1.43$ & $\$ 4.28$ & $\$ 2.85 \S$ & $\$ 0.12$ & $\$ 3.57$ & $\$ 3.45 \S$ & & \\
\hline Tier 2 & $\$ 10.00$ & $\$ 12.86$ & $\$ 2.86 \S$ & $\$ 13.81$ & $\$ 17.14$ & $\$ 3.33 \S$ & $\$ 2.86$ & $\$ 13.26$ & $\$ 10.40 \S$ & & \\
\hline Tier $3 \dagger$ & $\$ 0.00$ & $\$ 1.43$ & $\$ 1.43 \S$ & $\$ 0.00$ & $\$ 0.0$ & $\$ 0.00 \S$ & $\$ 0.00$ & $\$ 0.00$ & $\$ 0.00 \S$ & & \\
\hline Total copayment PPPM & $\$ 12.14$ & $\$ 19.81$ & $\$ 7.67$ & $\$ 15.24$ & $\$ 21.42$ & $\$ 6.18$ & $\$ 3.00$ & $\$ 16.83$ & $\$ 13.85$ & $\$ 11.44$ & $\$ 25.42$ \\
\hline $\begin{array}{l}\text { * Median values are reported because } \\
+ \text { Tier-3 copayment drugs represent }< \\
\text { participants have no purchases of ti } \\
\text { in both preperiod and postperiod is } \\
+ \text { Not statistically significant at } P<0.0 \\
\text { \& Represents a sum of medians across } \\
\text { converting group increased from } 0.4\end{array}$ & $\begin{array}{l}\text { highly ske } \\
\text { rchases by } \\
\text { median te } \\
\text { langes (pr } \\
\text { for each } s \\
\text { erall Rxs }\end{array}$ & $\begin{array}{l}\text { umber of } \\
\text { will pick } \\
\text { eriod vers } \\
\text { imary me } \\
\text { PM chang }\end{array}$ & $\begin{array}{l}\text { rescriptions } \\
\text { p changes } \\
\text { sure. Over } \\
\text { d from } 1.0\end{array}$ & $\begin{array}{l}\text { (Rxs); the } \\
\text { the non: } \\
\text { l) are stat } \\
\text { all differen } \\
\text { to } 1.28\end{array}$ & $\begin{array}{l}\text { data are } 0 \\
\text { ero potion } \\
\text { tically sig } \\
\text { mon are rep } \\
\text { mong all s }\end{array}$ & $\begin{array}{l}\text { ganized at } \\
\text { f a distribi } \\
\text { ificant at } 1 \\
\text { rted in the } \\
\text { udy subjec }\end{array}$ & $\begin{array}{l}\text { the persor } \\
\text { ution, henc } \\
\text { last colum } \\
\text { s). }\end{array}$ & $\begin{array}{l}\text { level, so } \\
\text { e the signi } \\
\text { n. (e.g., } n\end{array}$ & $\begin{array}{l}\text { nore than } \\
\text { icance ever } \\
\text { tile Rx use }\end{array}$ & $\begin{array}{l}\text { alf the } \\
\text { where th } \\
\text { in the }\end{array}$ & median \\
\hline
\end{tabular}

(4.8 absolute percent), and then the 3-tier comparison group (3.3 absolute percent). The generic use rates of women were $6.2 \%$ greater than those of men. Arthritics were more likely to use generic medications, while diabetics, hypertensives, and individuals with GERD were less likely to do so.

\section{Discontinuation Rates for Nonformulary Medications During the Postperiod}

Logistic regression was used to examine the predictors of discontinuation rates for nonformulary medication controlling for the factors outlined previously. As a high level of multicollinearity exists between pharmacy benefit structure and copayment difference for the nonformulary medications (Kendall's tau $=0.72$ ), the copayment difference variable was dropped from the analysis. Due to the small sample sizes of members taking an individual nonformulary medication, discontinuation rates are reported by disease state (and not by individual nonformulary medications). The mean copayment difference that members experienced in the preperiod and postperiod for the nonformulary medications was highest for the converting group $(\$ 24.21[+4.6])$ and were similar for the 3-tier $(\$ 12.53[+4.1])$ and 2-tier comparison group (\$12.41
[+11.1]). The overall discontinuation rate was $43.41 \%$, with the highest rate for the converting group (47.2\%). The remaining groups had similar discontinuation rates: $40 \%$ for the 2 -tier and $37 \%$ for the 3 -tier comparison group. The discontinuation rates for each disease state were also similar (results not shown).

The results of the logistic regression are shown in Table 5 . While the model was not very predictive (goodness-of-fit $\mathrm{C}$ statistic was 0.57 ), only pharmacy benefit structure was significantly associated with discontinuation behavior for nonformulary medications. Individuals in the converting group were 1.76 times more likely to discontinue their nonformulary medication during the postperiod than those in the 2-tier comparison group and 1.49 times more likely than those in the 3-tier comparison group. Copayment differences for individual nonformulary drugs in the preperiods and postperiods were not included in the logistic regression model; the discontinuation rates for nonformulary medications with increasing increments of copayment differences is shown in Figure 1. Even though there appears to be an increase in discontinuation rates with higher increments of copayment differences, the actual differences are small (between 1\% and 3\%) and not statistically significant. 


\section{TABLE 4 Maximum Likelihood Estimates for the Formulary Compliance Rates Model}

Variable

Preperiod and 7,386 in the Postperiod)

Estimate

Standard Error

( $N=7,311$ in the Preperiod and 7,386 in the Postperiod)

of the Estimate

$P$ value

Period by pharmacy benefit structure interaction term (preperiod)*

Preperiod: 2-tier interaction (who were in the 2-tier

0.8668

0.013

$<.0001$

comparison group in the preperiod)

Preperiod: 3-tier interaction (who were in the 3-tier

0.8775

0.008

$<.0001$

comparison group in the preperiod)

Preperiod: 2-tier interaction (who were targeted to convert

0.8131

0.006

$<.0001$

to a 3-tier pharmacy benefit structure in the postperiod)

Period by pharmacy benefit structure interaction term (postperiod)*

Postperiod: 2-tier interaction (who were in the 2-tier

0.8746

0.013

$<.0001$

comparison group in the postperiod)

Postperiod: 3-tier interaction (who were in the 3-tier

0.8881

0.008

$<.0001$

comparison group in the postperiod)

Postperiod: 3-tier interaction (who converted to a 3-tier

0.8695

0.005

$<.0001$

pharmacy benefit structure in the postperiod)

\begin{tabular}{|c|c|c|c|}
\hline Summary of preperiod/postperiod differences for formulary & & & \\
\hline Preperiod/postperiod difference: 2-tier who stayed in 2-tier & 0.008 & 0.013 & 0.6002 \\
\hline Preperiod/postperiod difference: 3-tier who stayed in 3-tier & 0.01 & 0.008 & 0.2692 \\
\hline Preperiod/postperiod difference: 2-tier who moved to 3-tier & 0.056 & 0.005 & $<.0001$ \\
\hline$\overline{18-25 \text { years } \dagger}$ & 0.07534 & 0.015 & $<.0001$ \\
\hline Over 65 years & 0.04009 & 0.011 & $<.0001$ \\
\hline CDI & 0.00290 & 0.001 & 0.0094 \\
\hline Diabetes & 0.06930 & 0.006 & $<.0001$ \\
\hline Arthritis & -0.02832 & 0.005 & $<.0001$ \\
\hline Hypertension & -0.02549 & 0.005 & $<.0001$ \\
\hline Gastroesophageal reflux disease (GERD) & -0.06304 & 0.005 & $<.0001$ \\
\hline
\end{tabular}

* Interaction term represents the combined effect of time period and pharmacy benefit structure.

$\dagger 26$ to 64 years is the reference group.

$¥ C D I$ score is centered in the model.

\section{Discussion}

This study examined the effects of implementation of a 3-tier pharmacy benefit copayment structure on certain medication utilization behaviors. Examining prescription utilization and costs for medications in tiers 1 to 3 showed that the overall generic use ratio increased by a range of 3.3 to 4.9 absolute percent, with smaller decreases observed in brand-name use, and a significant decrease in nonformulary use for the converting group. This finding is consistent with Motheral et al. who found an increase in use of prescription drugs in copayment tiers 1 and 2 and a modest decrease in the use of nonformulary medications (tier 3) when individuals moved from a $\$ 7 / \$ 12$ to a $\$ 8 / \$ 15 / \$ 25$ 3-tier plan. ${ }^{11}$ Patterns of use were not uniform among individual drug classes for the converting group; an increase in nonformulary use was found for symptomatic dis- eases states such as arthritis and GERD, where beneficiaries may (a) be reluctant to switch to lower-cost formulary alternatives for medications that have demonstrated therapeutic effects or (b) not use these medications continuously.

Consistent with Motheral's findings, prescription costs to the health plan for tier-1 and tier-2 medications also showed an increase for all 3 study groups during the postperiod, with greater increases for tier-2 medications and smaller increases for tier-3 medications. ${ }^{11}$ It appears that the implementation of a 3-tier plan may cause some shifting of medication costs away from tier-3 to tier-2 medications. As intended by the health plan, member copayments increased by $10 \%$ for the converting group and by approximately 3\% for both the 2- and 3-tier comparison groups. It therefore appears that a $10 \%$ increase in copayments experienced by the converting group did deter 
nonformulary use to a significant extent in the postperiod. Formulary compliance for all 3 of the study groups was high (above $80 \%$ ) and showed an increase of $5.6 \%$ for those in the converting group during the postperiod. The magnitude of the change in formulary compliance for the converting group is no doubt associated with the $5.3 \%$ lower formulary compliance rate for this group during the preperiod.

Differences in baseline formulary compliance rates may be a result of other unmeasured factors in addition to the variables included in these analyses. Possible causative or confounding factors may include the differences in prescribing patterns of physicians for the converting group compared to the other groups or consumer demand for nonformulary medications in this group. Differences in formulary compliance rates also differed among disease states, with the diabetics being the most formulary compliant and individuals with GERD being the least formulary compliant. It is possible that for "flare" diseases such as GERD, individuals are reluctant to switch to formulary alternatives, when they have their acid reflux under control. Another explanation could be that a larger percentage of all diabetic drugs have formulary status versus drugs for heartburn (GERD) for which a larger proportion are nonformulary.

Generic use rates increased for all 3 of the study groups, with the largest increase for the converting group ( 4.9 absolute percent), followed by the 2 -tier comparison group ( 4.8 absolute percent), and then the 3-tier comparison group (3.3 absolute percent; $P<0.001)$. In support of this finding, Motheral et al. also found an increase in the number of generic claims when copayments were increased by $\$ 5$ for brand-name medications and $\$ 2$ for generic medications in a particular 2-tier plan. ${ }^{20}$ Since all 3 of the study groups experienced some increase in their copayment amounts during the postperiod, it appears that members are more likely to purchase generic medications in response to the higher copayments. These increases in the rates of generic use may appear modest but, in fact, represent significant savings to the health plan and to health plan beneficiaries. An absolute increase of 5\% in generic utilization ratios can translate into millions of dollars in drug benefit savings for large health plans. These savings that accrue from increases in the ratio of generic prescriptions become larger over time as the cost of brand-name medications continues to increase.

Past research has shown that the removal of a nonformulary product resulted in an increase in the number of prescriptions for its substitutes and other products within other drug classes. ${ }^{21}$ This suggests that individuals do appear to be sensitive to formulary coverage of their medications and are likely to discontinue use of the nonpreferred drug when coverage no longer exists. Previous findings have reported a decreased rate of continuation with nonformulary medications after the implementation of a formulary (about 27\%); the rates of discontinuation in this study were higher, averaging about $40 \% .{ }^{22}$ In support of this finding, Nair et al. found, through a series of focus group examinations, that when beneficiaries are con-

\begin{tabular}{|c|c|c|}
\hline Variable $(\mathrm{N}=1,497)^{*}$ & $\begin{array}{l}\text { Odds Ratio } \\
\text { Estimate }\end{array}$ & $\begin{array}{c}95 \% \text { Wald } \\
\text { Confidence Interval }\end{array}$ \\
\hline \multicolumn{3}{|l|}{ Pharmacy plan type ${ }^{\prime}$} \\
\hline \multirow{2}{*}{$\begin{array}{l}\text { Converting group (2-tier moving to } \\
\text { 3-tier as the reference versus 2-tier } \\
\text { staying in 2-tier) } \\
\text { Converting group (2-tier moving to } \\
\text { 3-tier as the reference versus 3-tier } \\
\text { staying in 3-tier) }\end{array}$} & 1.76 & $(1.19,2.60)$ \\
\hline & 1.49 & $(1.14,1.95)$ \\
\hline Female $\ddagger$ & 1.18 & $(0.96,1.45)$ \\
\hline Age & 1.00 & $(0.99,1.02)$ \\
\hline CDI & 1.04 & $(0.99,1.09)$ \\
\hline Diabetes & 1.20 & $(0.91,1.59)$ \\
\hline Arthritis & 0.86 & $(0.47,1.56)$ \\
\hline Hypertension & 1.02 & $(0.68,1.52)$ \\
\hline Gastroesophageal reflux disease (GERD) & 0.85 & $(0.53,1.36)$ \\
\hline Dyslipidemia & 1.02 & $(0.67,1.55)$ \\
\hline \multicolumn{3}{|c|}{$\begin{array}{l}\text { * Final sample size after casewise deletion of missing data for all measures in the } \\
\text { model. } \\
+ \text { Converting group was compared to each of the comparison groups. } \\
\neq \text { Males were the reference group. }\end{array}$} \\
\hline
\end{tabular}

fronted with a decision to pay a higher copayment for their chronic disease medications, their most common response was to switch to a lower-cost formulary alternative after talking to their physician or pharmacist about the alternative medication. ${ }^{10} \mathrm{~A}$ linear relationship was not observed between the discontinuation rates of nonformulary medications and increasing increments of copayment differences. However, there was no attempt in this study to determine the cost or availability of medication substitutes (prescription-based or over-the-counter alternatives), making it impossible to draw conclusions about price elasticity for beneficiaries using formulary-based, brandname medications.

Patient behavior is complex and pharmacy benefit polices intended to change behavior may not always produce the intended effects. ${ }^{23}$ Formulary compliance rates and generic use rates for the converting groups increased by approximately $5 \%$, while nonformulary use decreased by a similar amount as well. The results of this study appear to support the notion of 3-tier plans where prescription use appears to have shifted to the lower copayment tiers, suggesting that economic disincentives in the form of higher copayments do, in fact, steer individuals to lower cost (copayment) medication alternatives.

There is some evidence to suggest that beneficiaries in 3-tier pharmacy benefit structures are less satisfied with their prescription drug coverage than those in 2-tier pharmacy benefit structures and have expressed intentions to disenroll from their heath plan if given the opportunity. ${ }^{24}$ The challenge for managed care 

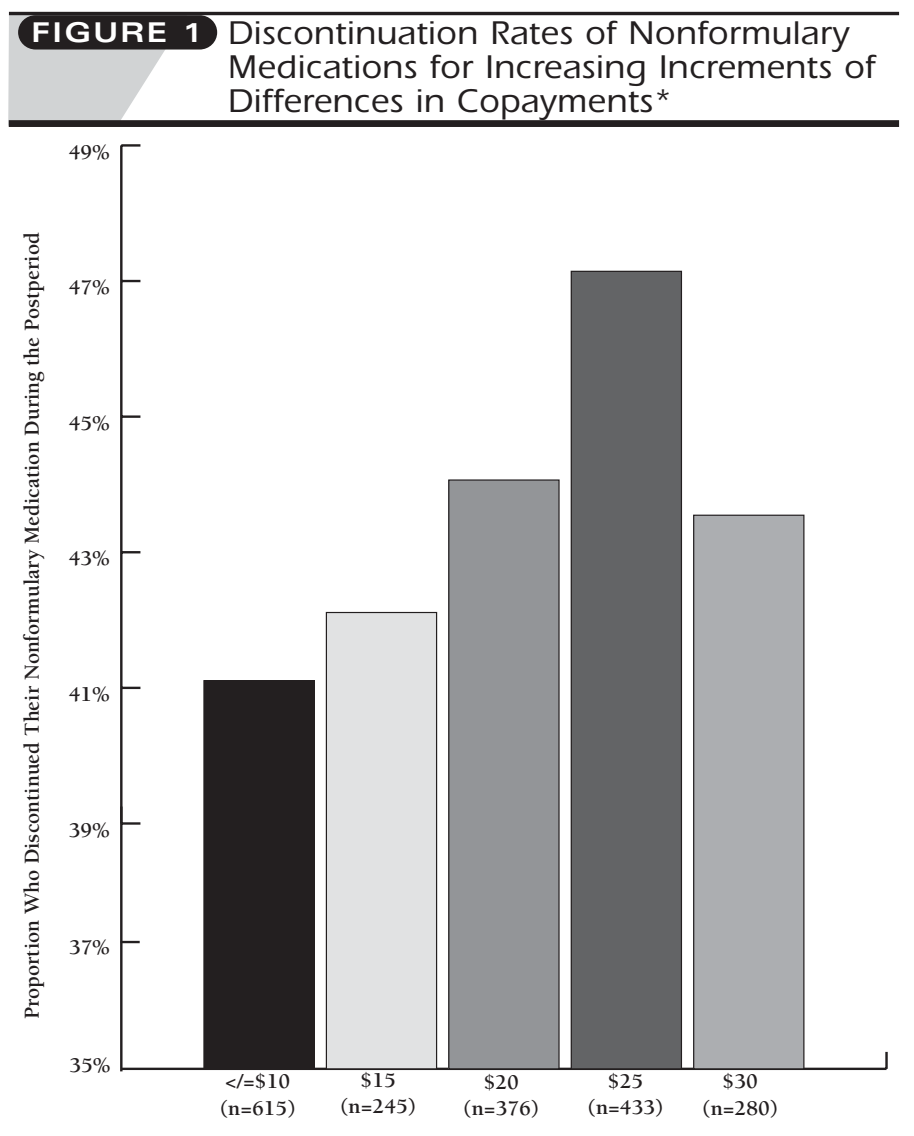

Increasing Increments of Copayment Differences (Preperiod Versus Postperiod)

* Preperiods versus postperiods, $n=1,949$ before case-wise deletion for missing covariates.

decision makers is to balance consumer attitudes about their pharmacy benefit plans, specifically dissatisfaction with increased cost sharing, with the changes observed in their medication utilization behavior, after the implementation of a 3-tier plan.

\section{Limitations}

In the analysis of the discontinuation rates for nonformulary medications, this study did not examine what actions individuals took after they discontinued the medication. These actions could have included (and are not limited to) switching to a brand or generic formulary alternative within the same drug class, switching to a medication in another drug class, discontinuing all drug therapy, purchasing an over-the-counter alternative, or making lifestyle modifications with diet and exercise. Future research can examine the actions of individuals who have discontinued their medication to determine if there are unintended consequences of discontinuation such as stopping drug therapy completely, which may lead to adverse health outcomes.

Several other potential limitations should be noted. The 3 study groups were not homogenous in patient demographic characteristics. Members in the 2-tier comparison group were older, and more than half of them were Medicare+Choice members (57.2\%) who are typically higher users of prescription drugs than the employed population. In contrast, subjects in the converting group and those in the 3-tier comparison groups had no Medicare+Choice members. Thus, the results of this study need to be interpreted in light of these differences among these groups. For example, there were no Medicare+Choice members in the 3-tier copayment groups, either converted from 2-tier or remaining in 3-tier copayment benefits, due to the combined effects of our inclusion criteria (i.e., continous enrollment and membership in one of only 3 comparison groups) and the elimination by the MCO of the 3-tier drug benefit for Medicare+Choice members in 2001, the postperiod of our study.

Individuals in all 3 of the study groups experienced some change in their prescription copayments during the postperiod. Thus, the designated comparison groups also experienced increases in their copayment along with the converting group. While controlling for these differences in copayment in the multivariate models seems an obvious choice, there are problems in doing so. Merely examining differences in copayments would not indicate what actual difference in cost sharing the individual faced for the medications at the various tiers at the time of decision making. In our study, the mean difference in copayment during the preperiod and postperiod for individuals in the converting group was $\$ 19.61$; for the 2-tier comparison group, it was $\$ 12.43$; and for the 3 -tier comparison group, it was $\$ 9.52$. Thus, the converting group experienced a 2 -fold increase in their copayments during the postperiod.

The study time frame of 14 months (7 months in the preperiod and 7 months in the postperiod) may not capture the full extent of the impact of a 3-tier pharmacy benefit structure on prescription utilization. Members may require some time to understand the changes in their prescription benefits in 2001 and understand how their copayments for prescription medications have changed. On the other hand, this study included only users of chronic medications who would most likely be aware of their pharmacy benefit changes. Earlier research used a 6-month follow-up period with satisfactory results. ${ }^{20}$ Our research was encumbered by the business practices of the managed care organization that was implementing additional pharmacy benefit plan changes starting in the fall of 2001, making it necessary to shorten the postimplementation measurement period.

There are inherent limitations in using pharmacy claims. In particular, the use of only pharmacy claims to identify individuals with chronic disease states is not optimal. When prescription claims are used as a proxy for a medical diagnosis, the issue of identifying members who do not have the disease is always a possibility, given the multiplicity of label and off-label purposes for drug products. ${ }^{25}$ Although a majority of the drug classes examined in this study are used for one indication primarily, in the case of hypertension, there may be some misclassification of individuals. 


\section{Conclusions}

The findings of this study reveal that members in a 2-tier pharmacy benefit structure who changed to a 3-tier pharmacy benefit structure experienced an absolute increase of $5.6 \%$ in formulary compliance rates relative to members who stayed in their respective 2- or 3-tier pharmacy benefit structure. Generic use increased in all 3 of the study groups, absolute changes in the range of 6 to 8 percent (adjusted changes in the range of $3.3 \%$ to $4.9 \%$ ), and the use of formulary brand-name products increased to a smaller extent ( 3 to 5 absolute percentage change). Nonformulary use appeared to decrease only for members who changed from a 2- to a 3-tier structure, apparently related to discontinuation of their use of nonformulary medications, compared to those who stayed in their former pharmacy benefit structures.

\section{ACKNOWLEDGMENTS}

We would like to acknowledge Steve Teusch and Robin Turpin from Merck and Company for their valuable input and comments.

\section{DISCLOSURES}

Funding for this research was provided by Merck and Company through the Academic Medicine and Managed Care Forum and was obtained by authors Kavita V. Nair, Robert J. Valuck, Pamela Wolfe, Julie M. Ganther, and Marianne M. McCollum. Nair served as principal author of the study. Study concept and design was contributed by Nair, Valuck, Wolfe, Ganther, McCollum, and author Sonya J. Lewis. Analysis and interpretation of data and drafting of the manuscript were primarily the work of Nair and Wolfe, and all authors contributed to the critical revision of the manuscript. Statistical expertise was contributed by Wolfe. Administrative, technical, and/or material support was provided by Mark Enders.

\section{REFERENCES}

1. Segedin DA. Three-tier copayment plans: design considerations and effectiveness. Drug Benefit Trends. 1999;11(9):43-52.

2. Penna P. Three-tier copay systems and consumer concentric care. J Managed Care Pharm. 1999;6(5):351-54.

3. Schneeweiss S, Maclure M, Walker AM, Grootendorst P, Soumerai S. On the evaluation of drug benefits policy changes with longitudinal claims data: the policy maker's versus the clinician's perspective. Health Policy. 2001;55:97-109.

4. Curtiss FR. Perspectives: drugs, PPOs, tiered cost share for beneficiaries and consumer preferences. J Managed Care Pharm. 2002;8(3):177.

5. Frank RG. Prescription drug prices: why do some pay more than others do? Health Aff. 2001;20(2):115-28.

6. Holdford D, Caroll NV. Consumer preferences for types of cost containment in prescription drug programs. J Managed Care Pharm. 2002;8(3):192-97.

7. Harris BL, Stergachis A, Reid D. The effect of copayments on utilization and costs of pharmaceuticals in a health maintenance organization. Med Care. 1990;28(10):907-17.

8. Fendrick MA, Smith DG. Chernew ME, Shah SN. A benefit based co-pay for prescription drugs: patient contribution based on total benefits, not drug acquisition cost. Am J Managed Care. 2001;7(9):861-67.

9. Giaquinta D. Pharmacy management and 3-tier copays: cost management or cost shifting? Managed Care Interface. 2000;13(5):64-65.
10. Nair KV, Ganther JM, Valuck RJ, McCollum M, Lewis SJ. Improving formulary compliance with managed care members. Drug Benefit Trends. 2002;14(7):44-46

11. Motheral, BR. Fairman, KA, R. Effect of a three-tier prescription copay on pharmaceutical and other medical utilization. Med Care. 2001;39(12):12931304

12. Malone DC, Billups SJ, Valuck RJ, Carter BL. Development of a chronic disease indicator score using a Veterans Affairs Medical Center medication database. IMPROVE Investigators. J Clin Epidemiol. 1999;52(6):551-57.

13. Fairman K, Motheral B. Evaluating medication adherence: which measure is right for your program? J Managed Care Pharm. 2000;6(6):499-504

14. Smith D. The effects of copayments and generic substitution on the use and costs of prescription drugs. Inquiry. 1993;30:189-97.

15. Jenrich RI, Schluchter MD. Unbalanced repeated measures model with structured covariance matrices. Biometrics. 1986;43:805-20.

16. Hosmer DW, Lemeshow S. Applied LogisticRegression. 2nd ed. New York: John Wiley and Sons, Inc.; 2000.

17. SAS Proc Mixed. Chapter 18: The MIXED procedure. SAS/STAT software: changes and enhancements through release 6.12, Cary, NC: SAS Institute Inc.; 1997:1167.

18. Trend of the Month: Average number of prescriptions by HMO's increases. Drug Benefit Trends. 2002;14(8):7.

19. Trend of the Month: More people are taking expensive drugs. Drug Benefit Trends. 2002;14(7):9.

20. Motheral BR. Henderson R. The effect of a copay increase on pharmaceutical utilization, expenditures and treatment continuation. Am J Managed Care. 1999;5:1383-94

21. Kreling DH, Knocke DJ, Hammel RW. The effects of an internal analgesic formulary restriction on Medicaid drug expenditures in Wisconsin. Med. Care. $1988 ; 27(1) ; 34-44$

22. Motheral BR, Henderson R. The effect of a closed formulary on prescription drug use and costs. Inquiry. 1999;36:481-91.

23. Reutzel TJ. Outpatient drug insurance: a framework to guide literature review, research and teaching. Am J Pharm Educ. 1998;62;1-11.

24. Nair KV, Wolfe P, Valuck RJ, McCollum M, Ganther, JM, Lewis, SJ., Impact of multi-tiered pharmacy benefits on medication adherence. Arlington, VA; May 2002. (Abstract featured in Value Health, May/June 2002; Vol. 5, No. 3:142).

25. Motheral BR, Fairman KA. The use of claims databases for outcomes research: rationale, challenges, and strategies. Clin Ther. 1997;19(2):346-66.

\section{Editor's Note}

The year 2020 marks the 25th anniversary of the Journal of Managed Care \& Specialty Pharmacy. To commemorate this milestone, we are publishing a series of articles that document the changes to the journal and profession over the past 2 and a half decades. Each month we reprint an original article from a previous year, dating back to 1995. The reprinted articles feature topics of significance in our industry. Each reprinted article is accompanied by a contemporary reflection that will consider the historical significance of the topic, as well as the current and future state.

Laura E. Happe, PharmD, MPH Editor-in-Chief 